\title{
Bingöl İl Merkezinde Taşkın Yayılım Alanlarının Coğrafi Bilgi Sistemleri ve HEC-RAS ile Belirlenmesi
}

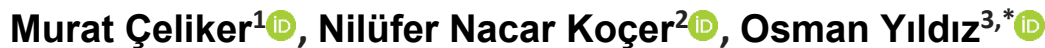 \\ ${ }^{1}$ Devlet Su İşleri Genel Müdürlüğü, 9. Bölge Müdürlüğü, 23000, Elazığ. \\ ${ }^{2}$ Fırat Üniversitesi, Mühendislik Fakültesi, Çevre Mühendisliği Bölümü, 23119, Elazığ. \\ ${ }^{3}$ Kırıkkale Üniversitesi, Mühendislik Fakültesi, Inşaat Mühendisliği Bölümü, 71450, Kırıkkale.
}

\section{Özet}

Taşkın, ülkemizde en sık görülen doğal afetler arasında yer almaktadır. Bu nedenle, taşkın yayılım alanlarının önceden belirlenmesi, taşkın riskinin azaltılması ve buna bağlı olarak can ve mal güvenliğinin sağlanması açısından çok önemlidir. Bu çalışmada, Coğrafi Bilgi Sistemleri (CBS) ve HEC-RAS yardımıyla Bingöl İl merkezinden geçen Çapakçur, Gayt ve Göynük çaylarının kent içerisinde oluşturacağ taşkın su derinliklerinin ve yayllım alanlarının belirlenmesi amaçlanmıştır. Bunun için, sentetik birim hidrograflardan elde edilen 2, 5, 10, 25, 50, 100, 500 ve 1.000 ylllık tekerrür sürelerine ait taşkın pik debileri kullanılarak HEC-RAS ile bu derelerin il merkezinden geçen kısımlarının hidrolik modellemeleri yapılmıştır. İl merkezine ait 1/1.000 ölçekli hali hazır haritalardan elde edilen verilerin modele tanımlanması ArcGIS üzerinde çalısan HEC-GeoRAS ile gerçeklestirilmistir. HEC-RAS yardımıyla elde edilen hidrolik model sonuçlarına göre CBS ortamında hazırlanan taşkın yayılım haritalarında, göz önüne alınan taşkın debilerinin sebep olduğu maksimum su derinliğinin 8,12-9,62 m, su yayllım alanının ise 635.402-1.561.982 $\mathrm{m}^{2}$ arasinda değiştiği görülmüştür. Elde edilen bu taşkın yayılım haritaları, bölgenin ileriye yönelik yerleşim ve kalkınma planları için önemli bir veri kaynağg niteliğgi taşımaktadır.

\section{Anahtar Sözcükler}

Taşkın, Taşkın Yayılım Haritası, CBS, HEC-RAS, Bingöl

\section{Determination of Flood Inuandation Areas in the City of Bingöl (Turkey) Using Geographic Information Systems and HEC-RAS}

\begin{abstract}
Flood is among the most common natural disasters in Turkey. For this reason, it is very important to determine the flood spreading areas in advance, to reduce the flood risk and to ensure the safety of life and property accordingly. In this study, it is aimed to determine the flood water depths and inundation areas of Çapakçur, Gayt and Göynük streams passing through Bingöl Province center with the help of Geographic Information Systems (GIS) and HEC-RAS. Thus, hydraulic models of these streams passing through the city center were developed by the use of HEC-RAS for the peak flows obtained from synthetic unit hydrographs with return periods of 2, 5, 10, 25, 50,100, 500 and 1,000 years. The data obtained from the up-to-date maps of the study area with 1/1,000 scale were defined to the model by HEC-GeoRAS working on ArcGIS. According to the flood inundation maps, which were prepared in the GIS environment using the hydraulic model results obtained with the help of HEC-RAS, the maximum flood water depth varies between 8.12 and 9.62, and the maximum flood inundation area ranges from 635,402 to 1,561,982 $\mathrm{m}^{2}$ for the flood peaks considered in the study. The flood inundation maps obtained in this study can be used as an important data source for the future settlement and development plans of the region.
\end{abstract}

$\underline{\text { Keywords }}$

Flood, Flood Inundation Map, GIS, HEC-RAS, Bingöl

\section{Giriş}

Türkiye'de ve diğer birçok ülkede insanların ekonomik ve sosyal hayatını etkileyen önemli doğal olaylardan biri de taşkındır. Türkiye'de büyük taşkınlara sebep olan başlıca etkenler; bölgesel iklim şartları, topoğrafik yapı, yağış drenaj alanının büyüklüğü, akarsu yataklarındaki yoğun yapılaşma, çarpık kentleşme ve kent içinden geçen akarsuların üzerlerinin kapatılması olarak sıralanabilir. Büyük havzalarda biriken kar kütlelerinin yağmur suları ile birleşimi, küçük havzalarda ise konvektif fırtınaların oluşturduğu şiddetli yağışlar büyük taşkınlara neden olmaktadır.

\footnotetext{
* Sorumlu Yazar: Tel: +90 (318) 3573576 Fax: +90 (318) 3572459

E-posta: mceliker23@gmail.com (Çeliker M), nkocer@firat.edu.tr (Nacar Koçer N), 
Genel olarak incelendiğinde; yerleşim alanlarındaki teknik ve ekonomik gelişmişlik, toprak kullanımı ve nüfus yoğunluğuna bağlı etkenler taşkın afetinin etkilerini arttırmaktadır. Yoğun şekilde gözlenen kentleşme ile birlikte bölgelerin hidrolojik karakteristikleri değişmekte ve buna bağlı olarak taşkınların büyüklüğü ve sıklığı artmaktadır (Özdemir 2007).

Dünya genelinde akarsu taşkınlarından kaynaklanan zararların azaltılması ve önlenmesi için çeşitli yapısal önlemlere ilave olarak geleneksel mühendislik tasarımları da önerilmiştir. Yapısal önlemler ile birlikte tabii dengeyi bozmayan ve taşkın büyüklüğünü artırmayan önlemler de taşkından korunma yöntemleri olarak kullanılmalıdır. Esasında, taşkın alanı içerisinde yeralan sosyal, çevresel ve ekonomik unsurlar, tam olarak nasıl bir taşkından korunma yolu veya yöntemi izleneceğine karar vermemize yardımcı olur. Yapısal önlem alınmasına karar verildiğinde taşkın problemlerinin çözümü; öncelikle tasarım debisinin elde edilmesi, bulunan debiye göre hidrolik hesaplamaların yapılması, yapısal sistemin seçilmesi ve seçilen sistemin tasarımından oluşan aşamaları içerir. Ülkemizde ve diğer birçok ülkede taşkından korunma için yapısal önlemler alınmış, bununla birlikte yapısal olmayan önlemlerin kullanımı da son yıllarda artmıştır. Çevrenin korunması ve sürdürülebilir kalkınma için, taşkın kaynaklı afet yönetimi planlarının sürekli yenilenmesi ve tüm korunma yöntemlerinin avantajlarını içeren bir çalışma ile mümkün olabilir. Buna göre; taşkına maruz kalma riskinden korunma, bunun mümkün olmadığı durumlarda ise bu riskin zararlarını bertaraf etmek, zararlar oluştuktan sonra etkilerini azaltmak ve tüm bunları tabii çevreyi koruyacak ve geliştirecek şekilde ve sürdürülebilir kalkınma ile uyumlu olarak uygulamak gerekir (Sarıbacak 2002; Plate 2002; Bacanli 2006).

Taşkın yayılım haritaları; taşkın yayılım alanlarının sınıflandırılması, arazi kullanımı ve imar planlama çalışmalarının hazırlanmasında birçok önemli temel parametreyi içermektedir. Dünyanın birçok bölgesinde daha görünür şekilde yaşanan iklim değişikliklerinin, mevcut su yapıları üzerindeki etkilerinin araştırılması konusu giderek önemli bir hale gelmiş durumdadır (FEMA 2009). Bu kapsamda yapılacak çalışmalar içerisinde taşkın yayılım haritalarının oluşturulması önemli bir yer tutmaktadır. Uzaktan Algılama (UA), Coğrafi Bilgi Sistemleri (CBS) ile hidrolojik ve hidrolik modelleme konularında kaydedilen ilerlemelere paralel olarak yapılacak çalışmalar ile özellikle meskun yerlerde taşkın risklerin azaltılması ve muhtemel zararların en aza indirilmesi mümkün olacaktır.

Son yıllarda yurt içinde ve yurt dişında, UA ve CBS teknikleri ile hidrolojik ve hidrolik modellerin beraber kullanılması sonucunda akarsu taşkını üzerine birçok araştırma ilgili literatürde yer almıştır. Aşağıdaki paragrafda bu çalışmalardan bazılarına ait özet bilgiler sunulmuştur.

Baga vd. (1999) Türkiye'de ilk defa CBS yardımıyla Çayboğazı nehir havzasının Fethiye İlçesi'nde taşkın yayılım haritalarını oluşturmak için Mike 11 hidrolik modelini kullanmıştır. Turan (2002) Bartın Ulus Havzası'nda taşkın risk durumunu incelemek için CBS ile Mike 11 programını beraber kullanmıştır. Tate vd. (2002) Texas eyaletindeki Waller Nehri'nde taşkın sahalarını belirlemek için CBS ve HEC-RAS programlarını kullanmıştır. Knebl vd. (2004) San Antonio Nehir Havzası'nda 2002 yılında meydana gelen büyük taşkın olayının modellemesi için CBS ve HEC-RAS yazılımlarını kullanmıştır. Onuşluel (2005) İzmir Karşıyaka İlçesi'ndeki Bostanlı nehir havzasının taşkın alanlarını CBS ve HEC-RAS yazılımları ile belirleyerek görseller oluşturmuştur. Özdemir (2007) Havran Çayı Havzası'nda ArcGIS, HEC-GeoRAS ve HEC-RAS yazılımları ile farklı senaryolara göre taşkın haritalarını hazırlamıştır. Usul (2008) Çayboğazı havzasının taşkın modellemesinde hidrolojik ve hidrolik modeller ile CBS tekniklerini birlikte kullanmıştır. Özcan vd. (2009) Sakarya havzasında taşkın alanlarının belirlenmesi ve risk yönetimi için CBS ve uzaktan algılama yöntemlerini birlikte kullanmıştır. Uçar (2010) Doğu Karadeniz Bölgesinde yeralan Değirmendere Havzası'nda, taşkın risk çalışmaları için ArcGIS ve HEC-RAS programlarını birlikte kullanmıştır. Kaya (2012) Giresun Pazarsuyu'nun taşkın yayılım haritalarının elde edilmesinde ArcGIS ve JFLOW yazılımlarını birlikte kullanmıştır. Akkaya vd. (2013) Rize Taşlıdere Bölgesi'nde ArcGIS ve HEC-RAS ile taşkınlar üzerine analizler yapmıştır. Nas ve Nas (2013) Harşit Çayı'nda CBS ve HEC-RAS ile farklı taşkın tekerrür süreleri için taşkın seviyelerini belirlemiştir. Bayazıt vd. (2014) Porsuk Çayı'nın Eskişehir il merkezinden geçen kısmında taşkın riskini incelemek için uzaktan algılama ve CBS yöntemlerini beraber kullanarak farklı taşkın tekerrür süreleri için HEC-RAS yazılımı ile hidrolik modellemeler gerçekleştirmiştir. Türkkan ve Korkmaz (2015) Bursa ilinden geçen Kaplıkaya Deresi'nin taşkın riskini belirlemek için CBS ve HEC-GeoRAS ve HECRAS yazılımlarını birlikte kullanmıştır. Yaylak (2016) Bitlis Deresi’nde taşkın risk analizi için ArcGIS, HEC-GeoRAS ve HEC-RAS yazılımlarını beraber kullanarak çeşitli taşkın tekerrür sürelerine ait hidrolik karakteristikleri ve su yüzeyi profillerini belirlemiştir. Shirzad (2017) Kocaeli Maden Deresi’nde taşkın riskini uzaktan algılama ve CBS teknolojilerini kullanarak incelemiştir. Bu amaçla gerekli olan su yüzeyi profillerinin hesabında HEC-RAS programını kullanmıştır. Çeliker (2018) Bingöl İl merkezinde Çapakçur Çayı taşkın alanlarının belirlenmesinde CBS teknikleri ve HEC-RAS yazılımını birlikte kullanmıştır. Uslu vd. (2018) Samsun'da Mert Irmağı ve yan kolu Yılanlıdere'nin çeşitli tekerrürlü taşkınlar için taşkın tehlike haritalarını Hec-GeoRAS ve HEC-RAS programlarını kullanarak elde etmiştir. Bu çalışmada oluşturulan taşkın yayılım haritaları ile 2014 yılında yapılan dere ıslah çalışması öncesi ve sonrası için taşkın yayılım alanları, taşkına maruz kalan bina, parsel ve nüfus değerleri karşılaştırılmıştır. Söz konusu ıslah çalışmalarının yeterli düzeyde olup olmadığı tartışılmıştır. El-Naqa ve Jaber (2018) Ürdün'de Wadi Attarat Um Al Ghurdan petrol imtiyaz sahasında CBS ve HEC-RAS yazılımlarını kullanarak çeşitli taşkın tekerrür sürelerine ait su yüzeyi profillerini modellemiştir. Maskong vd. (2019) Tayland'da Nakhon Ratchasima beldesinde CBS ve HEC-RAS yardımıyla çeşitli tekerrürlü taşkın debilerine ait taşkın yayılım haritalarını elde etmiştir. Gülbaz (2019) sayısal modeller kullanarak İstanbul Sazlıdere Havzası sınırları içerisinde yeralan Türkköse Deresi’nin taşkın yayılım haritasını elde etmiştir. 
Bu çalışma kapsamında, havza özelliklerinin modellenmesinde WMS, hidrolojik model için HEC-HMS ve hidrolik model için HEC-RAS programları kullanılmıştır. Havzada 3-5 Temmuz 2005 tarihlerinde meydana gelen şiddetli yağışlar sonucu Türkköse Deresi’nde akımın 8 m derinliğe, taşkın yayılımının ise 260 m genişliğe ulaştığı tespit edilmiştir. Ertürk ve Kaya (2019) Doğu Karadeniz Havzası'nda yeralan Kirazlı Deresi'nin taşkın tehlike alanlarının oluşturulması için HEC-RAS ile 1 ve 2 boyutlu modellemeler oluşturmuştur. Çalışmada, meteorolojik ve topoğrafik açıdan riskli bir bölgede yeralan Kirazlı Deresi üzerindeki mevcut ıslah yapılarının revize edilmesi gerektiği, taşkınlara karşı erken uyarı sistemlerinin ivedi şekilde devreye sokulması gerektiği sonuçlarına varılmıştır.

$\mathrm{Bu}$ çalışmanın amacı, CBS teknikleri ve HEC-RAS yazılımını birlikte kullanarak Çapakçur, Gayt ve Göynük çaylarının Bingöl kenti içerisinden geçen kısımlarında çeşitli tekerrürlü taşkın debilerinin oluşturacağı taşkın yayılım haritalarının elde edilmesidir. Böylece, çalışma sonucunda elde edilecek taşkın su seviyesi ve taşkın yayılım alanlarına ait bilgilerin, bölgede meydana gelecek muhtemel taşkın riskerinin azaltılmasına ve bölgenin uzun vadeli sosyoekonomik kalkınma planlarının hazırlanmasında önemli katkılar sağlaması beklenmektedir.

\section{Materyal ve Metot}

$\mathrm{Bu}$ çalışmada hidrolojik ve hidrolik çalışmalar ile ArcGIS ve HEC-RAS programları kullanılarak modellemeler gerçekleştirilmiştir. Böylece, dere düzenleme çalışmaları için ıslah öncesi ve ıslah sonrası elde edilen taşkın modellemesi sonuçlarına göre Bingöl İl merkezinde su altında kalan alanlar uydu görüntüsü ve imar planı ile örtüştürülerek analiz edilmiş, risk altındaki alanlar belirlenmiş ve geleceğe yönelik planlamalar için önerilerde bulunulmuştur.

\section{1. Çalışma Alanı}

Bingöl ili Doğu Anadolu Bölgesi Yukarı Fırat bölümünde yer alır (Şekil 1). İl merkezinin nüfusu 153.011, ilin nüfus yoğunluğu ise $\mathrm{km}^{2}$ başına 32 kişidir. Bingöl il merkezi, ortalama 1150-1250 m yükseklikte olup, ilin imar planı topoğrafik olarak $80 \mathrm{~km}^{2}$ 'lik kuzeyden güneye doğru eğimli düzlük bir alan üzerinde genişlemişstir (Avc1 2017; Avc1 vd. 2018). Jeolojik olarak genellikle bazaltik ve andezitik kayaçlar hakim kayaç türleri olarak düzlük ve dağlık alanlarda yüzeylenmiştir (Tarhan 1997). Meteorolojik verilere göre Bingöl'de yıllık ortalama sıcaklık $12,1^{\circ} \mathrm{C}$ ve yıllık yağış miktarı 873,7 mm olarak belirlenmiştir (DMİ 2017).

Bu çalışmada, Çapakçur Çayı, Gayt Çayı ve Göynük Çayı'nın Bingöl İl merkezinden geçen kısımları göz önüne alınmıştır. Şekil 1'de görüldüğü gibi Çapakçur ve Gayt çaylarının birleştikleri noktadan sonraki kısım Göynük Çayı olarak adlandırılmaktadır (URL-1 2020). Çapakçur Çayı doğu yönünde Bingöl İl merkezinde yerleşim bölgelerinin yoğun olduğu bölgelerden ve tarım alanlarından geçerek Gayt Çayı'na akmaktadır. Gayt Çayı ise Bingöl İl merkezinin kuzey kesimi boyunca meskun mahaller dışındaki bölgelerden geçmektedir. Gayt Çayı üst havzasında yeralan Gayt Barajı, mansap bölgelerindeki alanların taşkın riskini büyük ölçüde kontrol altına almaktadır. Göynük Çayı'nın geçtiği bölgelerde ise meskun alanlar çok az olup bu bölgeler daha çok tarımsal niteliklidir.

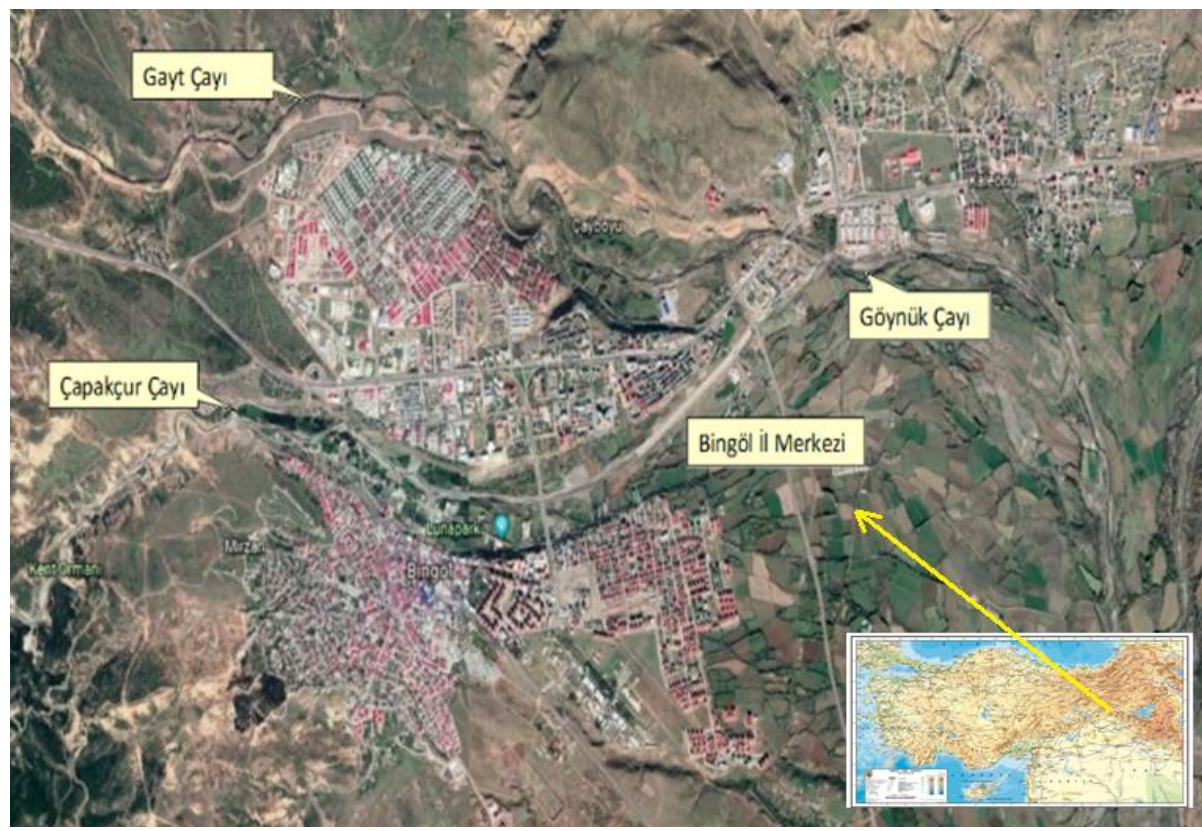

Şekil 1: Çapakçur, Gayt ve Göynük çaylarının Bingöl il merkezinden geçtiği kısımları gösteren uydu görüntüsü (URL-1 2020) 
Çapakçur Çayı'nda daha önce gözlenen büyük debilerin getirdiği alüvyon malzeme içerisindeki blokların nispeten büyük ve oransal olarak fazla olması bu derenin hayli yüksek bir hidrolik güce sahip olduğunu, dolayısıyla da 1slah edilmesi gerektiğini göstermektedir. 13 Nisan 2017 tarihinde Bingöl genelinde şiddetli sağanaklar sebebiyle metrekareye $52 \mathrm{~kg}$ yağış düşmesi sonucu Çapakçur Çayı'nda oluşan taşkın ve sel dolayısıyla, DSİ tarafindan dere üzerinde inşası devam etmekte olan tersip bentleri ve diğer sanat yapılarında çok ciddi boyutlarda tahribatlar oluşmuştur (Şekil 2). Ayrıca, Aşağı Çarşı Mevkii'nde yeralan bazı yapılarda önemli miktarda maddi hasar meydana gelmiştir. Taşkın sonrası DSİ tarafından yapılan hazırlanan raporda bu taşkının maksimum debi tekerrür süresinin 100 yıldan daha fazla olduğu tahmin edilmiştir (DSİ 2017).
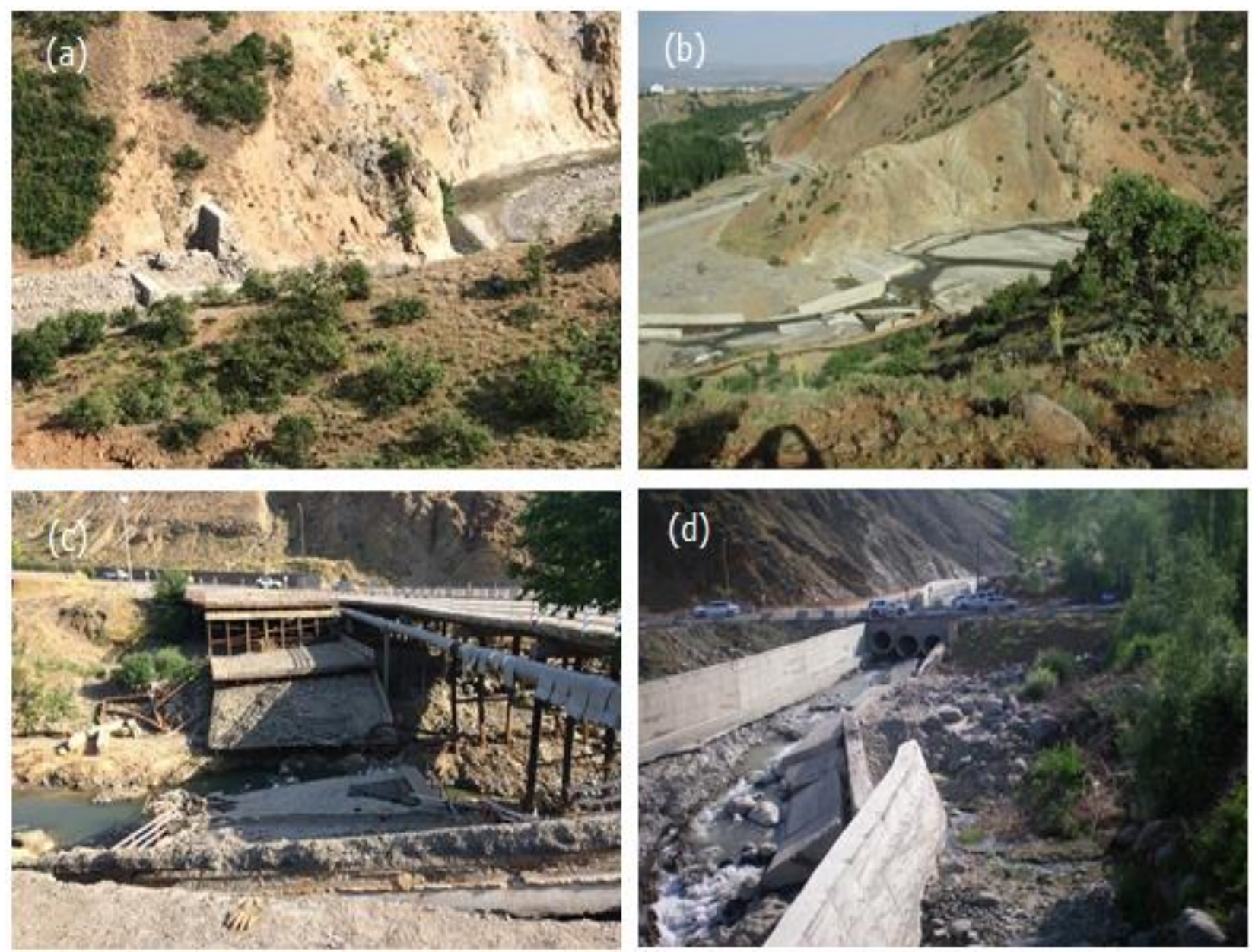

Şekil 2: 13.04.2017 tarihinde Çapakçur Çayı'nın taşması ve sel sonucu su yapılarında oluşan tahribatlar: (a) memba tersip bendi, (b) mansap tersip bendi, (c) akarsu geçiş köprüsü, (d) taşkın kontrol tesisi (Foto: DSi 9. Bölge Müdürlüğü)

\subsection{Taşkın Pik Debilerinin Hesaplanması}

Çapakçur ve Gayt çayları üzerinde akım gözlem istasyonları bulunmadığı için bu dere havzalarında farklı tekerrür sürelerine ait taşkın pik debilerinin tahmininde sentetik birim hidrograf yöntemi kullanılmıştır. Çalışmada, sayısal yükseklik modeli (DEM) ve TIN için altlık haritaları 1/1.000'lik hali hazır haritalardan, havza sınırı ve drenaj ağının oluşturulması için ise 1/25.000'lik standart topografik haritaları ve Google Earth görüntülerinden faydanılmıştır. DEM ve TIN verileri 10 piksel boyutunda oluşturulmuştur.

Gereksinim duyulan hidrolojik parametreler DSİ tarafından bölge için hazırlanan hidroloji etüt raporundan alınmıştır (DSİ 2017). Söz konusu raporda tavsiye edildiği gibi birim hidrografin hesabında süperpozesiz Mockus yöntemi tercih edilmiştir. Çapakçur ve Gayt çaylarının hidrometeorolojik yönden benzer olmaları sebebiyle taşkın pik debilerinin tahmini yalnızca Çapakçur Çayı havzası çıkış noktası için yapılmıştır. Bunu müteakiben, havzaların büyüklükleri göz önüne alınarak Gayt Çayı havzası için taşkın pikleri hesaplanmıştır. Daha sonra bu iki çayın birleştiği noktadaki pik debileri toplanarak Göynük Çayı pik debileri elde edilmiştir.

Çapakçur Çayı havza alanında yapılan müteferrik debi ölçüm değerlerinin mertebe olarak küçük olması sebebiyle baz akım değeri ihmal edilmiştir. 
Buna göre, Çapakçur Çayı havzası için Tablo 1'de verilen fiziksel ve hidrolojik parametreler göz önüne alınarak tahmin edilen $2,5,10,25,50,100,500$ ve 1.000 yıllık tekerrür sürelerine sahip pik debiler hidrolik modellemede kullanılmıştır.

Tablo 1: Çapakçur Çayı havzasının fiziksel ve hidrolojik özellikleri

\begin{tabular}{|c|c|c|c|c|c|c|c|c|c|c|}
\hline $\begin{array}{c}\mathrm{A} \\
\left(\mathrm{km}^{2}\right)\end{array}$ & $\begin{array}{c}\mathbf{L} \\
(\mathbf{k m})\end{array}$ & $\begin{array}{c}\mathbf{L C}_{\mathbf{C}} \\
(\mathbf{k m})\end{array}$ & $\begin{array}{c}S \\
(\%)\end{array}$ & $\mathrm{CN}_{\text {II }}$ & $\mathrm{CN}_{\text {III }}$ & $\begin{array}{c}\mathbf{T}_{\mathbf{c}} \\
\text { (saat) }\end{array}$ & $\begin{array}{c}\text { D } \\
\text { (saat) }\end{array}$ & $\begin{array}{c}\mathbf{T}_{\mathbf{p}} \\
\text { (saat) }\end{array}$ & $\mathbf{K}$ & $\begin{array}{c}\mathbf{Q p}_{\mathbf{p}} \\
\left(\mathbf{m}^{3} / \mathrm{s} / \mathbf{m m}\right)\end{array}$ \\
\hline 106 & 23,650 & 12,080 & 0,036 & 80 & 91 & 2,68 & 3,5 & 2,0 & 0,208 & 6,55 \\
\hline
\end{tabular}

\subsection{Hidrolik Modelleme}

Şekil 3'de verilen akış şemasına göre; taşkından etkilenecek yerlerin belirlenmesi için gerçekleştirilen hidrolik modelleme çalışmaları kapsamında oluşturulan tematik haritalar, ArcGIS 10.1 yazılımının bir uzantısı olan HEC-GeoRAS 10.1 ve HEC-RAS 5.0.3 kullanılarak hazırlanmıştır. CBS katmanları UTM (Universal Transverse Mercator) projeksiyonu (Zone 37) ve ED 50 (European Datum 1950) datumu ile jeo-referanslandırılmıştır. HEC-RAS ile yapılacak bir boyutlu hidrolik modellemeler için gerekli olan geometrik veriler, çalışma alanına ait 1/1.000 ölçekli sayısal haritalardan TIN formatında elde edilen sayısal yükseklik modelinden elde edilmiştir.

HEC-GeoRAS arayüz programı ile akarsuların güzergahı boyunca akış yolu, dere kıyıları, sel yatakları, köprüler, menfezler ve kesit katmanları tanımlanmıştır. Bingöl kent yerleşimini içine alacak şekilde Çapakçur Çayı'nın 6.672, Gayt Çayı'nın 3.806 ve Göynük Çayı'nın 544 metrelik kısımları modellemeye dahil edilerek çaylar üzerinde sırasıyla 135, 75 ve 11 adet en kesit göz önüne alınmıştır. Şekil 4'de görüldüğü gibi HEC-GeoRAS ile elde edilen geometrik veriler HECRAS programına otomatik olarak aktarılmıştır (URL-1 2020).

ArcGIS ile çalışma alanının TIN formatında sayısal yükseklik haritasının elde edilmesi

ArcGIS uzantısı HEC-GeoRAS ile elde edilen geometrik verilerin HECRAS'e otomatik olarak aktarılması

HEC-RAS'de akım verilerinin ve sınır koşullarının tanımlanması

HEC-RAS'de 1 boyutlu hidrolik model sonuçlarının elde edilmesi

Hidrolik model sonuçlarının HEC-GeoRAS ile CBS ortamına taşınması ve taşkın yayılım haritalarının ArcGIS ile elde edilmesi

Şekil 3: Hidrolik modelleme akış şeması 


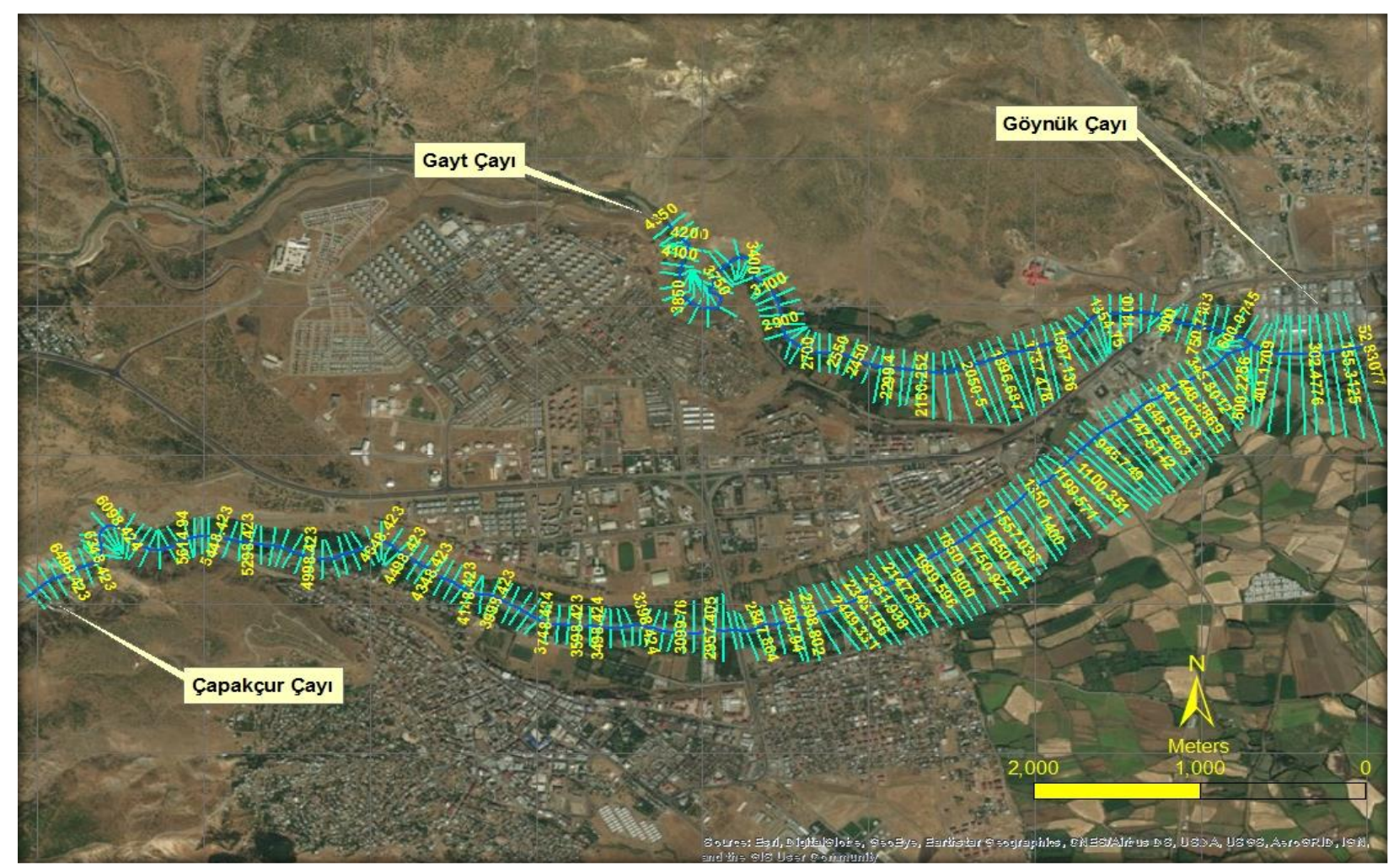

Şekil 4: Çalışma bölgesinde çaylar üzerinde seçilen en kesitlerin yerleşim planı üzerinde görünümü

Yapılan arazi incelemelerine göre; çalışma alanındaki akarsu yatakları genellikle iri çakıllı malzeme ile kaplıdır. Yataklar nispeten önemsiz düzeyde kıvrımlı ve orta dereceli şekilde sınıflanabilecek bir bitki örtüsüne sahiptir. Kanal şevleri yer yer ağaçla kaplı olup değişik aralıklarla en kesitlerde değişimlere rastlanmaktadır (Şekil 5). Bu faktörler göz önüne alınarak yapılan değerlendirmede modellemesi yapılan kanal kesitleri için Manning pürüzlülük katsayısı 0,085 olarak hesaplanmıştır.

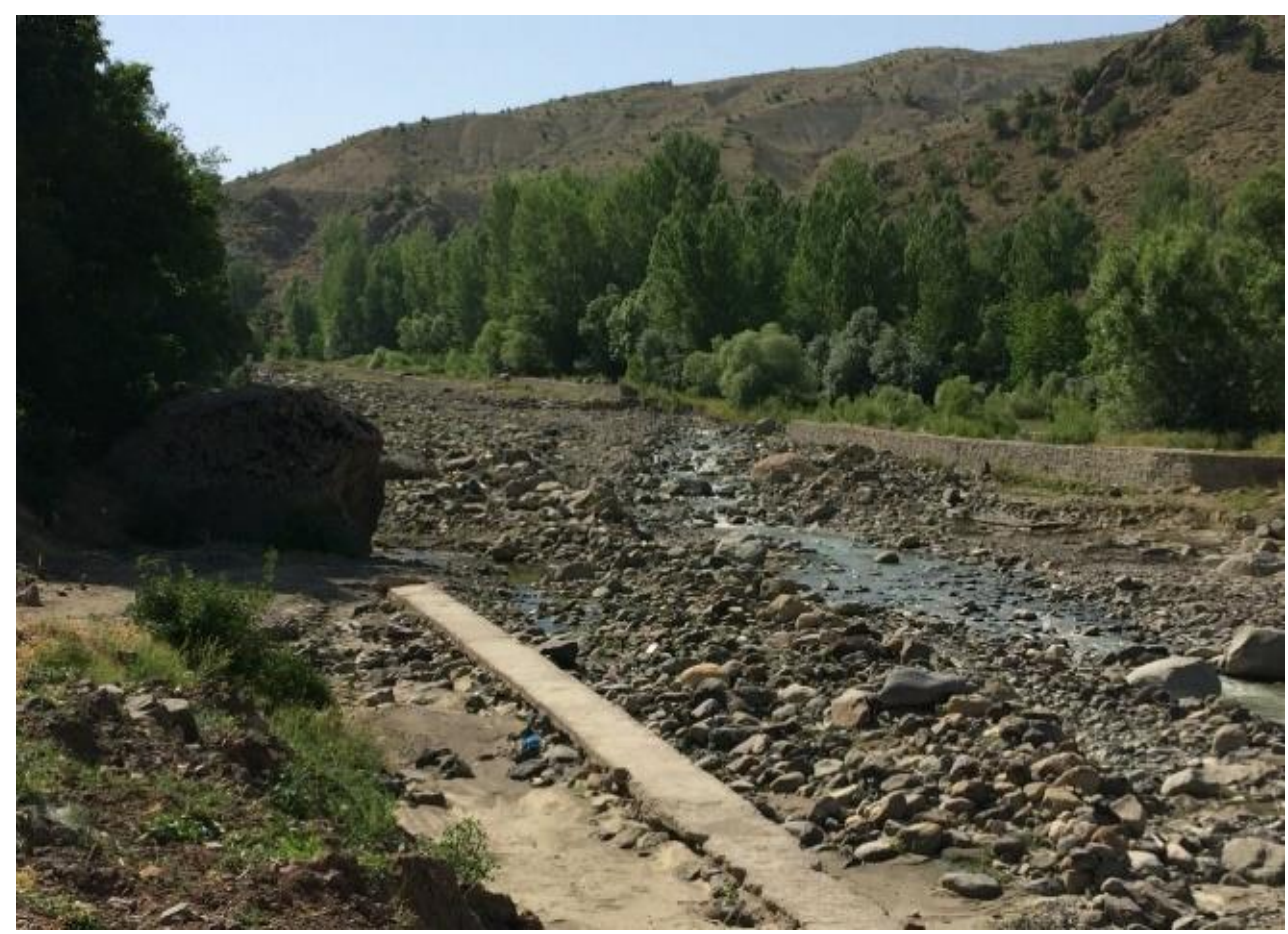

Şekil 5: Çapakçur Çayı memba kısmının genel görünümü tesisi (Foto: DSi 9. Bölge Müdürlüğü) 
HEC-RAS akım veri tanımlayıcısında bütün pik debiler için memba ve mansap akım sınır şartları üniform olarak kabul edilerek kararlı akım benzetimleri yapılmıştır (Şekil 6). Bu tabloda görüldüğü gibi Çapakçur, Gayt ve Göynük çaylarının modellemesi yapılan kısımlarına ait debiler memba kesitleri için tanımlanmıştır. Akım türü kararlı akım olduğundan kanal boyunca akım değerinde zamana göre bir değişim söz konusu değildir, yani akım debisi her kesitte aynı değeri almaktadır. Değişim yalnızca akım derinliği ve hız değerlerinde meydana gelmektedir.

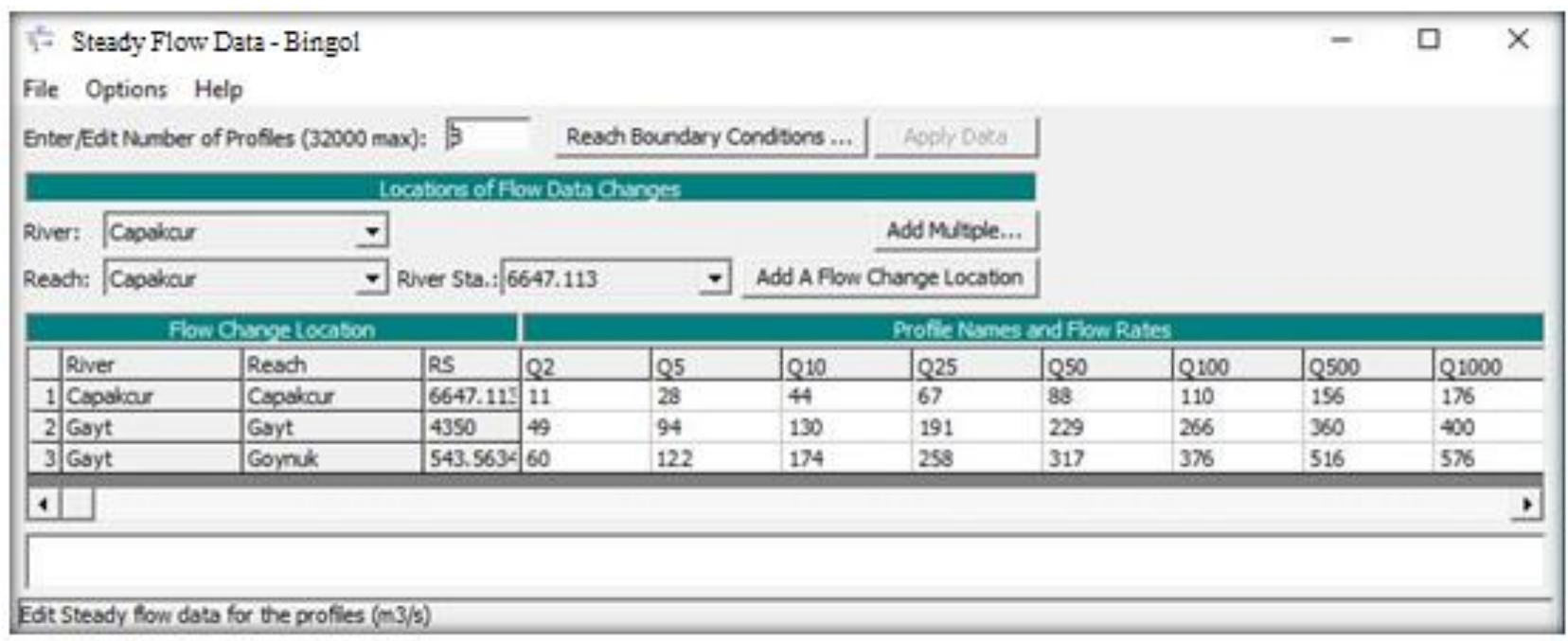

Şekil 6: Akım verilerinin HEC-RAS veri tanımlayıcına girilmesi

\section{Bulgular}

Taşkın yayılım haritalarının oluşturulması için gerekli olan taşkın su seviyesi kotları HEC-RAS çıktısı olarak hesaplanan su yüzeyi profillerinden elde edilmiştir. Buna göre maksimum su derinlikleri; $\mathrm{Q}_{2}$ taşkın debisine göre 8,12 m, $\mathrm{Q}_{5}$ debisine göre 8,36 m, Q ${ }_{10}$ debisine göre 8,56 m, Q 25 debisine göre 8,88 m, Q 50 debisine göre 9,06 m, Q Q 100 debisine göre 9,23 m, Q 500 debisine göre 9,46 m ve $Q_{1000}$ debisine göre 9,62 m olarak belirlenmiştir. Şekil 7 ve Şekil 8'de Çapakçur ve Gayt çaylarının memba bölgelerine ait örnek su yüzeyi profilleri görülmektedir.

Hesaplanan su yüzeyi kotları HEC-GeoRAS programına aktarıldıktan sonra ArcGIS yardımıyla her bir taşkın tekerrür süresine ait taşkın yayılım haritaları elde edilmiştir. Model sonuçlarına göre taşkın yaylım alanları; $\mathrm{Q}_{2}$ taşkın debisine göre $635.402 \mathrm{~m}^{2}, \mathrm{Q}_{5}$ debisine göre $790.196 \mathrm{~m}^{2}, \mathrm{Q}_{10}$ debisine göre $869.754 \mathrm{~m}^{2}, \mathrm{Q}_{25}$ debisine göre $1.001 .041 \mathrm{~m}^{2}, \mathrm{Q}_{50}$ debisine göre 1.121.430 $\mathrm{m}^{2}, \mathrm{Q}_{100}$ debisine göre 1.229.848 $\mathrm{m}^{2}, \mathrm{Q}_{500}$ debisine göre $1.423 .658 \mathrm{~m}^{2}$ ve $\mathrm{Q}_{1000}$ debisine göre 1.561.982 $\mathrm{m}^{2}$ olarak hesaplanmıştır. Şekil 9'da görüldüğü gibi taşkın tekerrür süresi arttıkça taşkın yayılım alanları da tedrici olarak artmaktadır (URL-1 2020). Yapılan incelemede, taşkın yayılımlarının dere kesit yüksekliğinin azaldığı ve genişlediği bölgelerde arttığı ve yine aynı şekilde su derinliklerinin de dere kesitlerinin daraldığı ve sanat yapılarının olduğu alanlarda arttığı görülmüştür. 


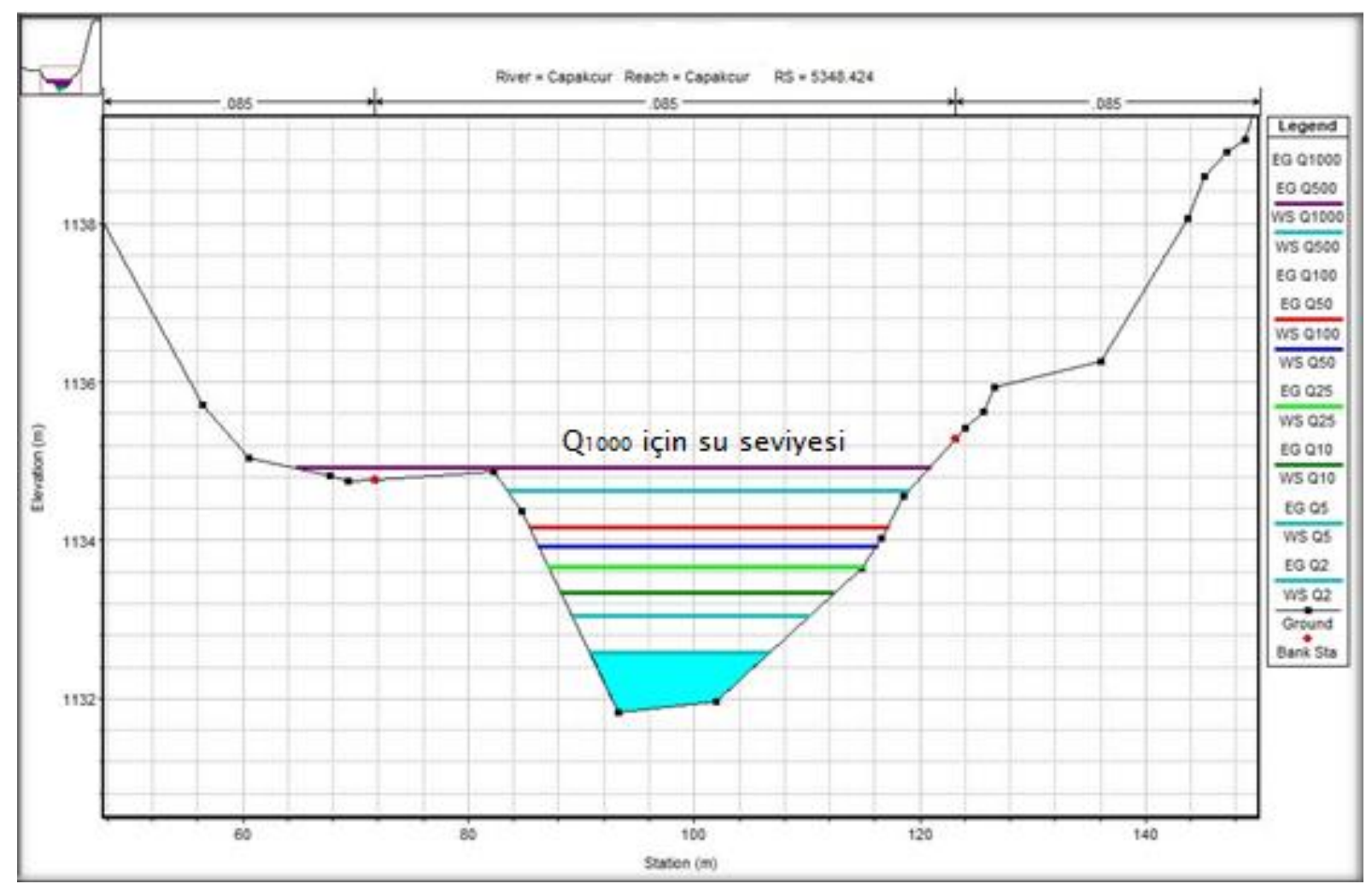

Şekil 7: HEC-RAS hidrolik modeli ile elde edilen Çapakçur Çayı için su yüzeyi profili

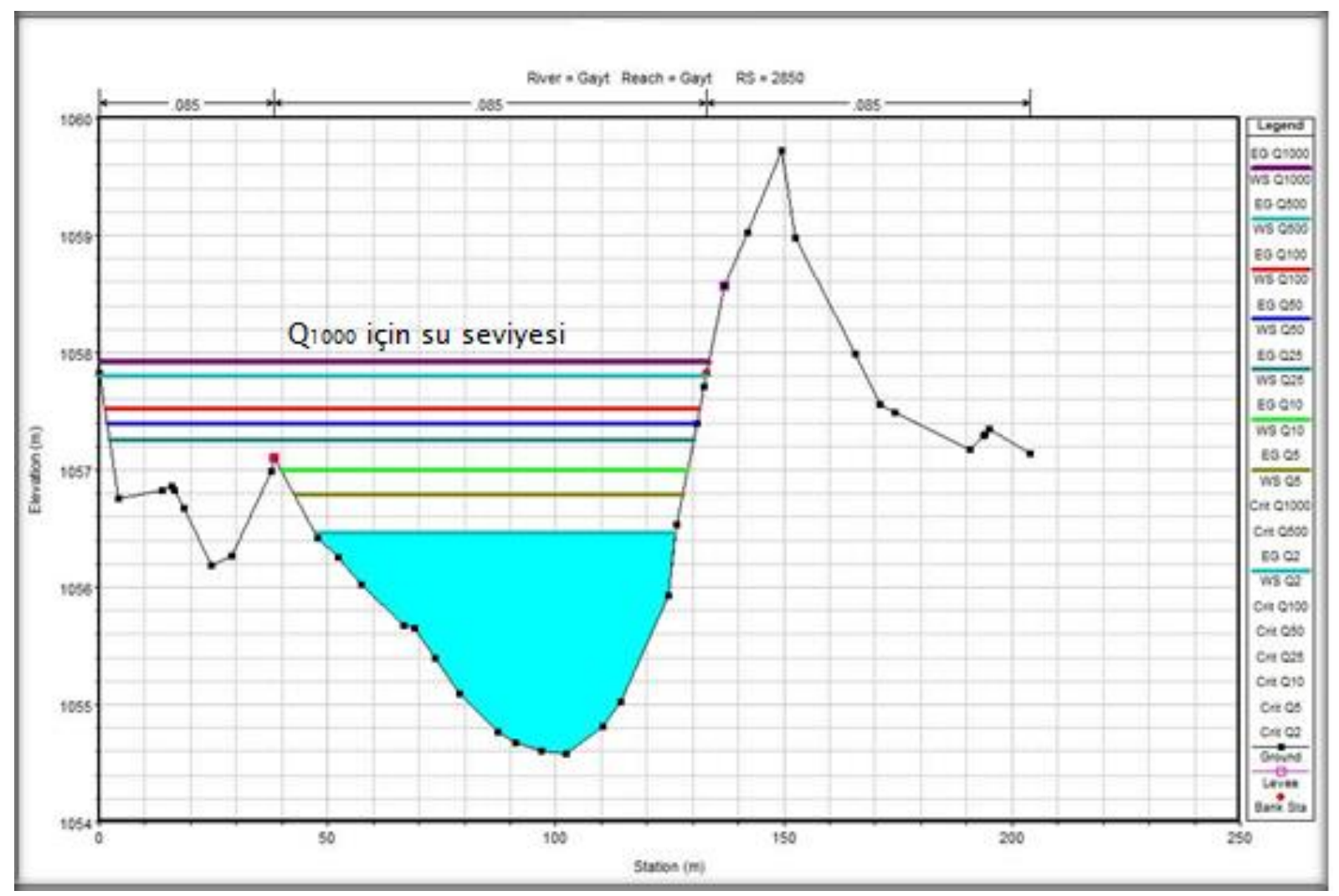

Şekil 8: HEC-RAS hidrolik modeli ile elde edilen Gayt Çayı için örnek su yüzeyi profili 


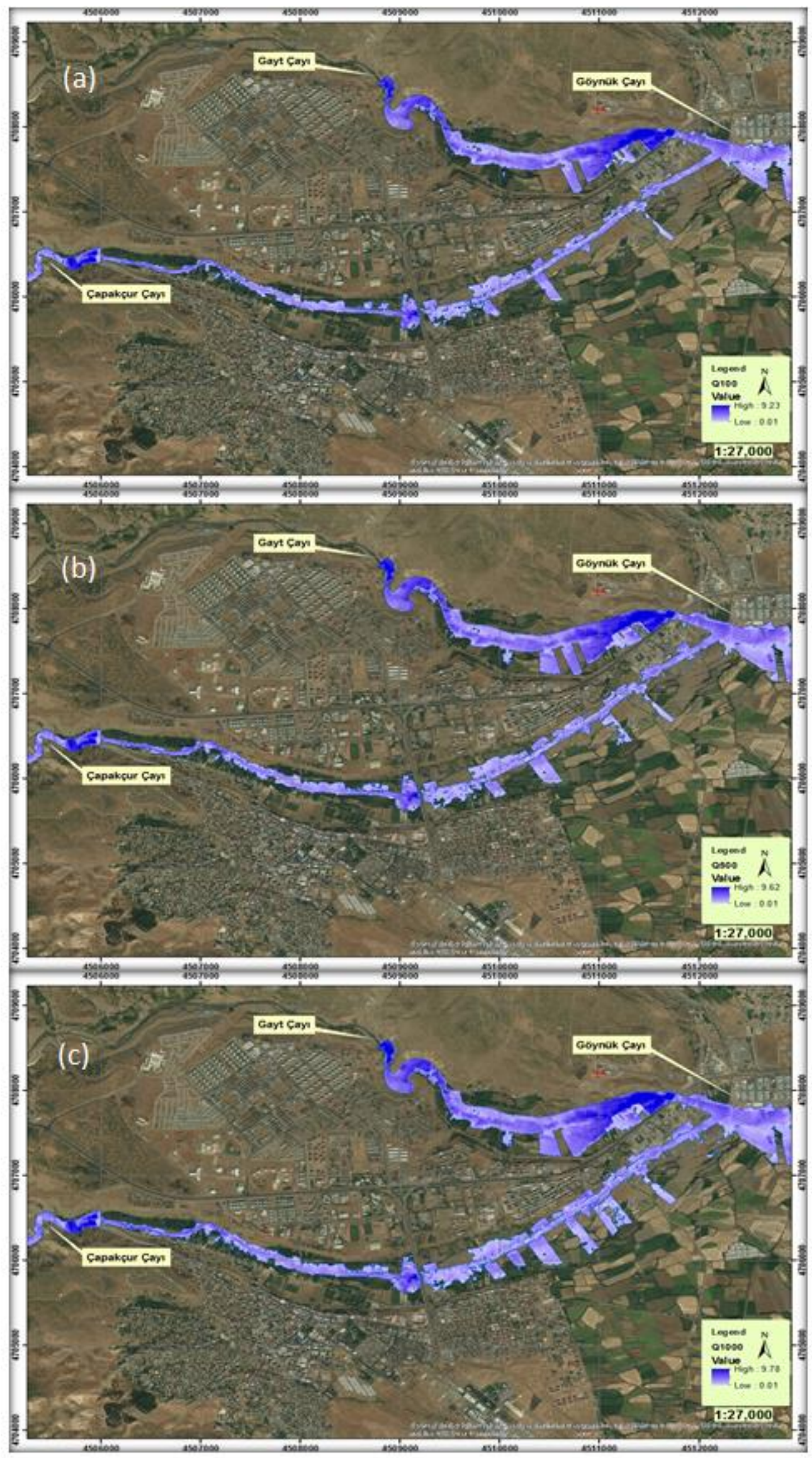

Şekil 9: Bingöl İı merkezinde farklı tekerrür süreli taşkınlar için elde edilen taşkın yayılım haritaları: (a) 100, (b) 500, (c) 1.000 yıl 
Elde edilen taşkın yayılım haritaları üzerinde yapılan değerlendirmeye göre; özellikle 100 yıl ve daha büyük tekerrür süreli taşkınlarda Bingöl İl merkezindeki bazı binaların, şehir merkezinde yeralan Çapakçur Çayı üzerindeki karayolu köprüsünün ve nispeten önemli bir oranda tarım arazisinin taşkın riski altında olduğu görülmüştür. Çapakçur Çayı'nın yatağının geniş olması, imar planının dere yatağı kotundan daha üst kotlara göre planlanması yapılar ve tarım arazileri üzerinde taşkın etkisini nispeten azaltmaktadır. Buna rağmen geçmiş tarihlerde yaşanan taşkınların sebep olduğu maddi zararlar göz önüne alındığında bu çay üzerinde dere ıslahının yapılması gerekliliği ortadadır.

Çapakçur ve Gayt Çayının Bingöl il merkezinden geçtiği tüm kısımlar için DSİ tarafından 1slah projesi geliştirilmiştir. Çalışma çıktısı olarak verilen haritanın ölçeği göz alınacak olursa, ıslah projesine ait genel vaziyet planı ancak dere merkezinden geçen bir çizgi hattı şeklinde gösterilebilir. Söz konusu 1slah çalışması kapsamında, Şekil 10'da görülen dikdörtgen ve kompozit en kesitli kaplamalı kanal tasarımları önerilmiştir. Bu çalışmamızda, tahmin edilen taşkın pik debileri ile yapılan hidrolik modelleme sonuçlarına göre; önerilen kanal en kesitlerinin taşkın riskini önlemede yeterli olduğu görülmüştür. 1.000 yıl tekerrür süreli taşkın debisi için verilen kanal kesitlerinde su seviyesinin maksimum 3,2 m civarında olduğu hesaplanmıştır (Şekil 10).

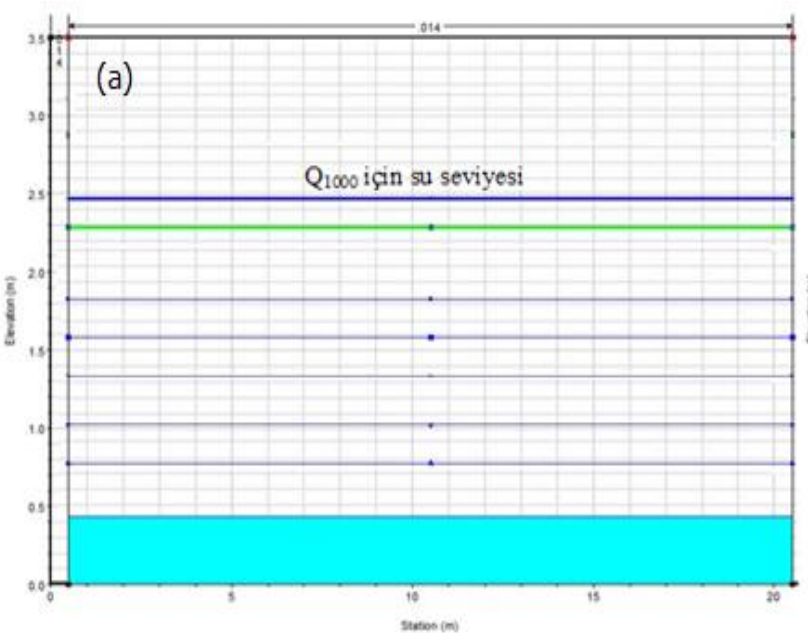

Şekil 10: Çapakçur Çayı için tasarlanan kanallarda hesaplanan su seviyeleri: (a) dikdörtgen en kesit, (b) kompozit en kesit

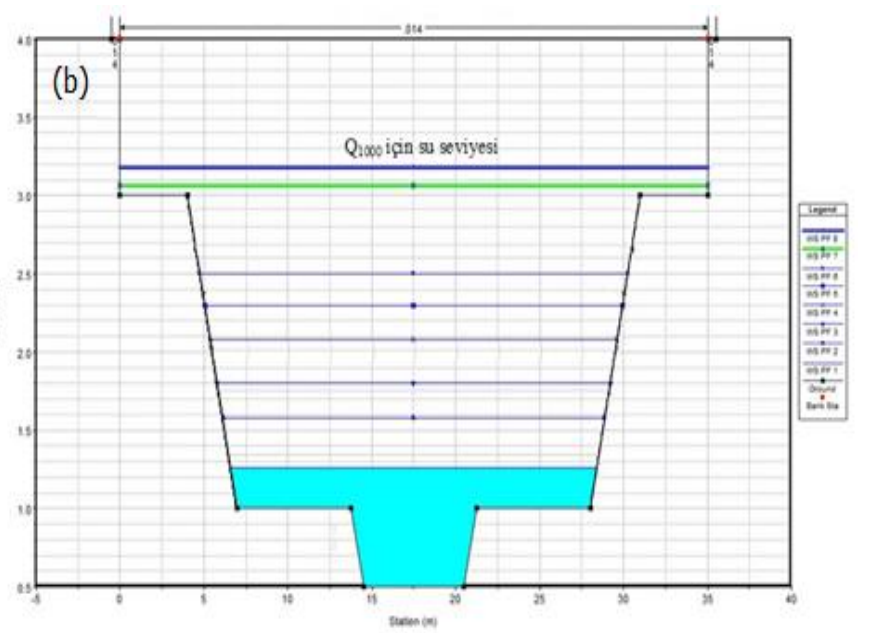

$$
\text { (1) }
$$

\section{Tartışma ve Sonuç}

Bu çalışmada, Bingöl İl merkezinden geçen Çapakçur, Gayt ve Göynük çaylarının 2, 5, 10, 25, 50, 100,500 ve 1.000 yıllık tekerrürlü taşkınlara ait taşkın yayılım haritaları elde edilmiştir. Sentetik birim hidrograf yöntemi ile hesaplanan taşkın piklerinin su yüzeyi profilleri HEC-RAS yazılımı ile hesaplanmıştır. Taşkın yayılım haritalarının oluşturulmasında HEC-GeoRAS ve ArcGIS programları birlikte kullanılmıştır. Burada elde edilen model sonuçlarının çalışılan bölgenin geleceğe yönelik yönetim ve planlaması için çok önemli veriler sağladığı görülmektedir. Taşkın yayılım alanlarının belirlenmesi ile bu alanlardaki yapılaşmanın ciddi taşkın riskleri taşıdığı görülmektedir.

CBS ortamında elde edilen taşkın yayılım haritaları üzerinde yapılan değerlendirmeye göre; maksimum su derinliğinin göz önüne alınan taşkın debileri için taşkın su seviyelerinin 8,12-9,62 m arasında, su yayılımının ise 635.402-1.561.982 $\mathrm{m}^{2}$ arasında değiştiği görülmüştür. Buna göre, Bingöl kent merkezinde bazı yapıların ve önemli bir miktarda tarım arazisinin taşkın riski altında olduğu görüldüğünden, özellikle Çapakçur ve Gayt çaylarında gerekli dere 1slah çalışmalarının DSİ tarafından en kısa zamanda tamamlanması gerekmektedir. Gayt Çayı'nın memba kısmında inşa edilen Gayt Baraj'ının bu dere üzerinde oluşacak taşkınları büyük ölçüde kontrol altına aldığı görülmüştür. Buna ilave olarak, DSİ tarafından planlama çalışmaları halen devam etmekte olan Çapakçur Barajı'nın da Çapakçur Çayı'nın çalışılan bölgedeki olası taşkınları büyük oranda kontrol altına alacağı öngörülmektedir.

HEC-RAS ile yapılan hidrolik modelleme çalışmalarında Çapakçur Çay'ının sediment debisi göz önüne alınmamıştır. Nispeten yüksek oranda sediment taşıma kapasitesine sahip olan çayın taşkın kotlarını önemli derecede etkileyeceği düşünülerek yeterli sayı ve kapasitede tersip bendi ve brit yapıları inşa edilmelidir. Ayrıca, toprak erozyonuna engel olmak için havzada ağaçlandırma çalışmalarına önem verilmelidir.

Çalışma sonuçlarına göre; Bingöl İl merkezinde göz önüne alınan çaylar üzerine inşa edilen karayolu sanat yapılarının büyük taşkın debilerini geçirecek kapasitede olmadığı görülmüştür. Nitekim, 13 Nisan 2017 tarihinde Bingöl'de meydana gelen taşkının bölgedeki su yapılarına ciddi zararlar verdiği, bazı köprü ve tersip bentlerinin yıkıldığı bilinmektedir. Taşkın yayılım haritalarında görüldüğü gibi, söz konusu sanat yapılarının olduğu bölümlerde kesit daralmasından dolayı taşkın yayılımı önemli derecede artmaktadır. Dolayısıyla, bu tür yapıların dere kesiti daraltılmadan taşkın debilerine göre yeniden projelendirilmesi gerekmektedir. 
DSİ tarafından yürütülen dere ıslahı çalışmalarında, en kesitlerin daraldığı yerlerde akım hızının nispeten büyük olacağı göz önüne alınarak buralarda oyulmalara karşı kanal kaplaması için yüksek dozlu beton kullanılması yerinde olacaktır. $\mathrm{Bu}$ çalışmada, ArcGIS, HEC-GeoRAS ve HEC-RAS yazılımlarının taşkına maruz kalacak alanların belirlenmesinde kolayca entegre edilebileceği görülmüştür. Ayrıca, son yıllarda farklı alanlarda yoğun bir şekilde kullanılan CBS tekniklerinin taşkın modelleme çalışmalarında etkin bir araç olarak kullanılabileceği anlaşılmıştır.

\section{Teşekkür}

Bu çalışmada kullanılan fiziksel ve hidrolojik verilerin temininde yardımcı olan DSİ 9. Bölge Müdürlüğü’ne teşekkür ederiz.

\section{Kaynaklar}

Akkaya U., Saraylı S., Doğan E., Akçalı E., Akpınar A., Yıldırım M.S., (2013), Rize Taşlıdere'nin taşkın analizinin yapılması, Taşkın ve Heyelan Sempozyumu Bildiriler Kitabı, 24-26 Ekim, TMMOB İnşaat Mühendisleri Odası Trabzon Şubesi, Trabzon, ss.503512.

Avcı V., (2017), Bingöl İli’nde nüfus ve yerleşmelerin yükselti basamaklarına göre dă̆llışı, Bingöl Üniversitesi Sosyal Bilimler Enstitüsü Dergisi, 7(13), 201-222.

Avcı V., Esen F., Kıranşan K., (2018), Bingöl İli’nin fiziki coğrafya özellikleri, Bingöl Araştırmalari Dergisi, 4(2), 9-40.

Bacanlı Ü., (2006), Taşkın zararlarını azaltma, önleme yöntemleri ve Denizli İli örneği, I. Ulusal Taşkın Sempozyumu Tebliğler Kitabı, 10-12 Mayıs, DSİ Genel Müdürlüğü, Ankara, ss.95-106.

Baga İ., Usul N., Sorman Ü., (1999), Application of MIKE 11 Model on Çayboğazı basin in Turkey, DHI Third User Conference, Denmark.

Bayazıt Y., Bakış R., Koç C., Kaya T., (2014), Porsuk Çayı’nın Eskişehir İli taşkın haritalarının Coğrafi Bilgi Sistemleri ile oluşturulması, Uluslararası Katılımlı IV. Ulusal Baraj Güvenliği Sempozyumu Bildiriler Kitabı (Editörler: Emiroğlu M.E., Tunç M.), 9-11 Ekim, Elazı̆̆, ss.731-737.

Çeliker M., (2018), Bingöl Çapakçur Deresi taşkın alanlarının Coğrafi Bilgi Sistemleri (CBS) ile belirlenmesi, Yüksek Lisans Tezi, Fırat Üniversitesi, Fen Bilimleri Enstitüsü, Elazığ

DMİ, (2017), Devlet Meteoroloji Işsleri Genel Müdürlüğü, http://www.mgm.gov.tr, [Erişim 15 Ekim 2019].

DSİ, (2017), Çapakçur Çayı Taşkını Teknik Raporu, DSİ Genel Müdürlüğü, Ankara.

Ertürk, E., Kaya, N., (2019), Taşkın tehlike alanlarının oluşturulması: Trabzon İli Vakfikebir İlçesi Kirazlı Deresi örneği, Fırat Üniversitesi Mühendislik Bilimleri Dergisi, 31(2), 337-344.

El-Naqa A., Jaber M., (2018), Floodplain analysis using ArcGIS, HEC-GeoRAS and HEC-RAS in Attarat Um Al-Ghudran oil shale concession area, Jordan, J. Civil Environ Eng., 8(5), 1-11.

FEMA, (2009), Risk Mapping, Assessment, and Planning (Risk MAP) Multi-Year Plan: Fiscal Years 2010-2014, Fiscal Report to Congress, Washington, D.C., USA.

Gülbaz S., (2019), Sayısal modeller ile taşkın yayılım harıtasının oluşturulması ve risk altında olan alanların belirlenmesi: Türkköse Deresi örneği, Doğal Afetler ve Çevre Dergisi, 5(2), 335-349.

Kaya Ç.M., (2012), Giresun Pazarsuyu örneğinde, Coğrafi Bilgi Sistemleri ve uzaktan algılama entegrasyonu ile taşkın risk haritalarının üretilmesi, Yüksek Lisans Tezi, Karadeniz Teknik Üniversitesi, Fen Bilimleri Enstitüsü, Trabzon.

Knebl M.R., Yang Z.L., Hutchison K., MaidmentD.R., (2004), Regional scale flood modeling using NEXRAD rainfall, GIS, and HECHMS/RAS: A case study for The San Antonio River Basin Summer 2002 storm event, Journal of Environmental Management, 75(4), 325-336.

Nas S., Nas E., (2013), Taşkın alanlarının Coğrafi Bilgi Sistemleri yardımıyla belirlenmesi ve risk analizi: Harşit Çayı (Gümüşhane) örneği., Taşkın ve Heyelan Sempozyumu Bildiriler Kitab1, 24-26 Ekim, TMMOB İnşaat Mühendisleri Odası Trabzon Şubesi, Trabzon, ss. 405-419.

Onuşluel G., (2005), Floodplain management based on the HEC-RAS modelling system, Doktora Tezi, Dokuz Eylül Üniversitesi Fen Bilimleri Enstitüsü, İzmir.

Özcan O., Musaoğlu N., Şeker D., (2009), Tașkın alanlarının CBS ve uzaktan algılama yardımıyla belirlenmesi ve risk yönetimi: Sakarya Havzası örneği, TMMOB Harita ve Kadastro Mühendisleri Odas1 12. Türkiye Harita Bilimsel Teknik Kurultay1, 11-15 Mayis, Ankara, ss.11-15.

Özdemir H., (2007), SCS CN Yă̆ış-akış modelinin CBS ve uzaktan algılama yöntemleriyle uygulanması: Havran Çayı örneği (Balıkesir), Ankara Üniversitesi Coğrafi Bilimler Dergisi, 5(2), 1-12.

Maskong H., Jothityangkoon C., Hirunteeyakul C., (2019), Flood hazard mapping using on-site surveyed flood map, HEC-RAS V.5 and GIS Tool: A case study of nakhon ratchasima municipality, Thailand, International Journal of GEOMATE, 16(54), 1-8.

Plate E., (2002), Flood risk and flood management, Journal of Hydrology, 267(1-2), 2-11.

Sarıbacak Ü., (2002), Water surface profiles in nonstructural flood mitigation, Yüksek Lisans Tezi, Orta Doğu Teknik Üniversitesi Fen Bilimleri Enstitüsü, Ankara.

Shirzad M.R., (2017), Taşkın riskinin uzaktan algılama ve CBS teknolojileri ile değerlendirilmesi: Kocaeli Maden Deresi örneği, Yüksek Lisans Tezi, Kocaeli Üniversitesi, Fen Bilimleri Enstitüsü, Kocaeli.

Tarhan N., (1997), 1/100.000 Ölçekli Türkiye Jeoloji Haritalarl, Erzurum G 31 ve G 32 Paftaları, Maden Tetkik Arama Enstitüsü Genel Müdürlüğü, Jeoloji Etütleri Dairesi, Ankara.

Tate E.C., Maidment D.R., Olivera F., Anderson D.J., (2002), Creating a terrain model for floodplain mapping, Journal of Hydrologic Engineering, 7(2), 100-108. 
Turan B., (2002), Obtaining inundation maps by integration of GIS and hydrologic-hydraulic model, Yüksek Lisans Tezi, Orta Doğu Teknik Üniversitesi Fen Bilimleri Enstitüsü, Ankara.

Türkkan G.E., Korkmaz S., (2015), Kaplıkaya Deresi'nin sayısal model ile taşkın analizi., VIII. Ulusal Hidroloji Kongresi Bildiriler Kitabı (Editörler: Yenigün K., Gümüş V., Gerger R., Aydoğdu M.H., Sepetçioğlu M.Y.), 8-10 Ekim, Harran Üniversitesi, Şanlıurfa, ss.62-69.

Uçar İ., (2010), Trabzon Değirmendere havzası'nda coğrafi bilgi sistemleri ve bir hidrolik model yardımıyla taşkın analizi yapılması, Yüksek Lisans Tezi, Gazi Üniversitesi Fen Bilimleri Enstitüsü, Ankara.

URL-1, (2020), ArcGIS Online Basemap, https://www.arcgis.com/home/group.html?id=702026e41f6641fb85da88efe79dc166\# overview, [Erișim 12 Nisan 2020].

Uslu G., Sesli F., Uzun B., (2018), Coğrafi bilgi sistemleri ile taşkın tehlike haritalarının belirlenmesi, Kent Akademisi, 11(4), 545558.

Usul N., (2008), Çayboğazı Havzası'nda hidrolojik-hidrolik model ve CBS ile taşkın çalışması, Taşkın, Heyelan ve Dere Yataklarının Korunmas1 Konferans1 Bildiriler Kitabı, 7-8 Ağustos, Çevre ve Orman Bakanlığı Devlet Su İşleri Genel Müdürlüğü XXII. Bölge Müdürlüğü, Trabzon, ss.147-159.

Yaylak M.M., (2016), Coğrafi Bilgi Sistemleri (CBS) yardımıyla Bitlis Deresi taşkın risk analizi, Yüksek Lisans Tezi, Bitlis Eren Üniversitesi, Fen Bilimleri Enstitüsü, Bitlis. 